HOLANDA, F. Cidade, paisagem, arquitetura. Thésis, Rio de Janeiro, v. 1, n. 1, p. 105-111, jan/jun. 2016

\section{Cidade, Paisagem, Arquitetura}

Frederico de Holanda

Frederico de Holanda (n. 1944, Recife, Brasil), arquiteto (UFPE, 1966), PhD em Arquitetura (Universidade de Londres, 1997). Professor Titular do Departamento de Teoria e História da Arquitetura e do Urbanismo, Faculdade de Arquitetura e Urbanismo, Universidade de Brasília, onde trabalhava desde 1972, tendo se aposentado em 2014. Continua como Professor Colaborador na mesma instituição. Investiga relações entre configuração da arquitetura e uso dos espaços pelas categorias sociais (classes, gêneros, gerações), nas edificações e na cidade. Orientou nove bolsistas de Iniciação Científica, 26 mestres e sete doutores. Coordena o Grupo de Pesquisa Dimensões Morfológicas do Processo de Urbanização (http://www.unb.br/fau/dimpu/). É autor de: O espaço de Exceção, baseado em sua tese de doutorado (Edunb, 2002); Arquitetura e Urbanidade (org.) (ProEditores Associados Ltda, 2003; $2^{a}$ Edição, FRBH, 2011); Brasília: cidade moderna, cidade eterna (FAU/UnB, 2010), pelo qual recebeu o prêmio ANPARQ 2010 (Associação Nacional de Pesquisa e Pós-Graduação em Arquitetura e Urbanismo) na categoria Livro texto integral - Menção Honrosa; o livro bilíngue (português/inglês) Oscar Niemeyer: de vidro e concreto / of glass and concrete (FRBH, 2011); o e-book Exceptional Space (em inglês), baseado em sua tese de doutorado (FRBH, 2011); Ordem e desordem: arquitetura e vida social (org.) (FRBH, 2012); 10 mandamentos da arquitetura (FRBH, 2013).

$\mathbf{N}$ ão costumo iniciar uma resenha sobre um trabaIho acadêmico por questões de forma. Como se esta fosse a cereja do bolo, deixada para o final. Entretanto, na tese de Renata Campello Cabral questões de excelente forma saltam à vista desde a Introdução. Nada de "nós majestáticos" ou voz passiva (frequente e inevitavelmente ambígua no discurso acadêmico afinal, quem fala? O autor? Outros a que ele se refere?). Não. Primeira do singular sempre quando está a autora a falar. Tampouco procurem por lista numerada, enfadonha, redundante de um "objetivo geral" e uma pletora de "objetivos específicos". Não encontrarão, por descartáveis, se a questão da pesquisa está bem definida no corpo do texto, como aqui. O discurso é claro, direto, amigável com o leitor - contudo preciso. E conciso: em quatro capítulos, mais a Introdução e as Conclusões, dá o recado em 198 páginas. Poucos, pouquíssimos escorregões de elegância na escrita aparecem aqui e ali, facilmente corrigíveis.

O eixo da tese está no conceito de ambiente em Gustavo Giovannoni (1873-1947), italiano, engenheiro de formação, cuja obra abrangeu da reflexão teórica à sua tradução em diplomas legais que facultassem a aplicação do conceito na identificação e preservação 
do patrimônio cultural na Itália. A inovação está no alargamento que Giovannoni opera no conceito de ambiente, até incluir a paisagem natural que emoldura, contém, contribui para configurar o artefato humano ou o espaço total no qual vivemos.

Como motivação central, Renata aponta lacunas de conhecimento em vários níveis, e faz sua escolha. Antes disso, está seu "interesse pelo significado das palavras" e, pesquisadora brasileira, nas relações entre Giovannoni e nosso país (indico entre aspas citações literais da tese, salvo quando uso palavras com conotações especiais, distinção que, espero, fique clara). Que polissemia esconde o vocábulo ambiente? Giovannoni contribui na Carta de Atenas (1931) no ponto referente à "valorização dos monumentos". O interesse de Renata pelo documento se dá "sobretudo por ele ser o único laço de contato de uma contribuição giovannoniana com o Brasil". O item refere a "fisionomia das cidades, sobretudo na vizinhança de monumentos antigos", e o interesse começa no fato de o termo na versão francesa falar em entourage, ser traduzido no Brasil por proximidade, e na versão italiana estar como ambiente.

A noção de ambiente foi o ponto de partida, mas o desenvolvimento da tese levou Renata a focar o que viria a ser a contribuição mais original do trabalho: relações entre o conceito do pensador e a sua aplicação prática, pelas contribuições de Giovannoni no campo legislativo. Revelou-se um campo pouco explorado, aqui ou alhures.

As relações de Giovannoni com os campos disciplinares pelos quais passeia são também interessantes. A exemplo de outros grandes estudiosos da arquitetura, o italiano também não provém do campo da arquitetura - é engenheiro de formação. Contudo, tem importante papel na "criação de um estatuto autônomo da história da arquitetura em relação à história da arte", é partícipe na criação de importantes periódicos, como Palladio (1937), "primeira revista inteiramente dedicada à história da arquitetura na Itália e no mundo".

A "conquista" (minhas aspas) de pensadores oriundos de outras áreas para o campo disciplinar da arquitetura não é nova. Mas é fenômeno curioso. No Brasil, Evaldo Coutinho é bacharel em direito de carteirinha, mas filósofo de fato. Autor do emblemático $O$ espaço da arquitetura (1970), Coutinho aplica à Arte do Espaço o método filosófico; na Filosofia, é considerado por seus pares um dos mais originais pensadores brasi- 
leiros. Da Inglaterra, vem-nos Bill Hillier, bacharel em literatura, e a Space Syntax Theory [Teoria da Sintaxe Espacial], contribuição teórica das mais marcantes no campo da arquitetura no último quartel do séc. $X X$ (e em plena aplicação e desenvolvimento nos quatro cantos do mundo). Ambos, Coutinho e Hillier, pensadores revolucionários. Antes deles, lembrem, no Brasil, particularmente na primeira metade de séc. $X X$, a contribuição à configuração urbana dos engenheiros Saturnino de Brito, Prestes Maia, Antônio Baltar, Mário Leal Ferreira...

Ao seleto grupo de pensadores originais junta-se Giovannoni, como se, de vez em quando, fosse preciso refresh - ou "reiniciar" (perdoem a metáfora informática) - o pensamento arquitetônico pela ótica de "estranhos no ninho", mais ágeis ao desfazer-se de preconceitos arraigados no campo - se é que os tiveram um dia. Fique claro: isso não é ampliar vitruvianamente o campo da arquitetura na direção de outros olhares e práticas disciplinares, fazendo a arquitetura tratar de "relógios" a "catapultas" - ou "da colher à região", como queriam nossos pioneiros do séc. XX - mas aprofundar o próprio campo, em termos específicos.

Definição do campo disciplinar $\mathrm{x}$ relações com outras áreas é tema recorrente em nossos encontros acadêmicos. A tese de Renata também o aborda. Quiçá possamos identificar duas tendências, exemplificadas em dois de nossos mais importantes congressos, em suas recentes edições: o Seminário de História da Cidade e do Urbanismo e o Encontro Nacional da ANPARQ (que premiou esta tese).

Nos SHUs consolida-se a visão de "urbanismo" como campo multidisciplinar (o tema foi abordado em várias ocasiões). Não por acaso, os seminários nascem em uma escola de arquitetura (UFBA) e são desde então promovidos por outras similares. Afinal, nossos cursos são quase sempre de "arquitetura e urbanismo", embora "urbanismo", neles, não dê conta do caráter multidisciplinar do campo. Mesmo assim, como desconsiderar aspectos morfológicos da cidade ao tratar do fenômeno? Como ignorar que uma das mais fortes maneiras pelas quais a cidade nos impacta é pela sua realidade física, concreta, espacial-volumétrica? Que ela é o "mais importante artefato construído pelos humanos" (Bill Hillier)? Não se estranhe, pois, arquitetos tomarem a dianteira no trato dos aspectos morfológicos, mas também, reconhecendo a multidimensionalidade do fenômeno, ampliarem a visão a outras facetas do campo, e as pesquisarem, promoverem, exporem 
nos SHUs. (Há diversidade de público, mas há muitas carinhas amigas comuns a ambos os congressos.)

Nos ENANPARQs, e quando se trata da escala urbana (outras escalas arquitetônicas são tocadas), o foco está em aspectos da configuração das cidades. (Decerto, há muitas maneiras de se estudar a configuração, porém como subdisciplinas do campo disciplinar: temos inequivocamente um núcleo disciplinar - o núcleo da arquitetura - que investiga o fenômeno, quer pelas causas, quer pelos efeitos.) Não diria que foi feliz casualidade a tese de Renata ter concorrido (e sido premiada) no ENANPARQ - ela pertence ao núcleo disciplinar correlato. Em tempo: ela também foi agraciada com o Prêmio CAPES Tese este ano, na área de Arquitetura.

Para seguir na ilustração, vejam a pesquisa capitaneada por Ana Maria Fernandes sobre os trabalhos realizados pelo engenheiro e urbanista baiano Mário Leal Ferreira, formado em 1914 pela Escola Politécnica da Bahia, junto ao Escritório do Plano de Urbanismo da Cidade do Salvador (EPUCS). Novamente, Mário Leal é urbanista na acepção multidisciplinar dos SHUs. (O estado atual da fascinante pesquisa foi apresentado no último SHU, quando foi lançado o livro correlato: ACERVO DO EPUCS: contextos, percursos e acessos, organizado por Ana.) Mário reuniu em torno de si e do EPUCS ampla equipe para tratar do planejamento da cidade de Salvador, considerando aspectos de infraestrutura urbana, higiene, transportes, economia, relações meio natural $x$ meio artificial, impactos na natureza etc. O trabalho, excepcional e raro no Brasil dada a sua abrangência, as teorias adotadas, e as concepções e desenho de cidade nele desenvolvidos, é até hoje considerado a mais importante experiência de planejamento urbano soteropolitano do século $X X$.

É de outro tipo a contribuição de Giovannoni. Seu interesse pela arquitetura - melhor, pela arquitetura da cidade - fá-lo desde cedo importar-se com aspectos morfológicos dela. Sua visão de arquitetura é ampla: desde a criação da primeira Escola Superior de Arquitetura (Roma, 1920), em que foi protagonista, propugnava pelo "arquiteto integral", com uma "bagagem técnica, científica e artística, que marcará a forma de ensino de arquitetura na Itália ao longo do séc. XX". Entretanto, sua obra - teórica e prática - o aproxima mais da "tradição ENANPARQ" que da "tradição SHU". Foca e aprofunda o estudo da configuração urbana, particularmente quanto às relações "velha" x "nova" cidade, e "cidade" $x$ "paisagem" - ou ambiente, como termo inclusivo. $E$, ainda aqui, nova precisão de foco: 
as questões são antes, digamos, "expressivas" (ou "culturais", ou "superestruturais") que "práticas" (ou "econômicas", ou "funcionais"). Nas primeiras, sobressaem questões da memória coletiva ("simbólicas"), imagéticas (um Kevin Lynch avant la lettre- e quanto!), "afetivas" (a identidade psicológica de um lugar - seu genius loci), estéticas.

Seria esticar a corda afirmar que os SHUs alinham-se predominantemente à tradição do urbanisme francês, da urbanistica italiana, do urban planning anglófono, termos que implicam "um significado mais amplo, compreendendo não apenas o 'fato material', mas o complexo das disciplinas que têm por objeto a cidade, como higiene urbana, estatística, legislação, economia, política, dentre outras"? E que os ENANPARQs alinham-se mais à tradição germânica veiculada pelo termo Städtebau, à inglesa do town planning ou, meIhor, do urban design (onde duas vertentes sobressaem: a escola da Urban Morphology e a da Space Syntax), à francesa do l'art de bâtir les villes, à italiana da edilizia cittadina, todas mais coladas ao "fato material" da "construção urbana"? Mesmo com superposições e ambiguidades, podemos identificar predominância francófona nos conferencistas internacionais convidados para os primeiros eventos, e anglófona para os segundos. O mesmo acontece quanto à articulação internacional dos colegas participantes, num e noutro evento. Seria talvez esticar mais ainda a corda dizer que Giovannoni está mais para um enanparquiano que um shuiano?... (Ai, esta doeu!)

Atuando de 1913 (suas primeiras publicações) a 1947 (seu falecimento), surpreende o "silêncio de sarcófago" (Nelson Rodrigues, não Renata) que por décadas cobriu o trabalho de Giovannoni, aqui e além-mares. Entender o silêncio é outra motivação de Renata: talvez mais um exemplo de como a ideologia dominante do Movimento Moderno - e seus sonhos delirantes de tabula rasa - reprimiu quem via na cidade pré-moderna valores naquele momento insuspeitados. A visão causou o furor de ideólogos como Bruno Zevi, para quem a obra de Giovannoni estaria "destinada ao esquecimento", ou "nem mesmo [a] uma recordação duradoura para além da geração de seus alunos". O carinho para com preexistências urbanas e paisagísticas de Giovannoni fez Zevi interpretar aquelas posições como de "ódio pela arquitetura moderna". Idiossincrasias (ou ideologias?) induzem leituras enviesadas.

Para vários estudiosos (p.ex. Françoise Choay), o véu começa a ser levantado a partir dos anos 1980, bem depois, portanto, de textos críticos ao urbanismo moderno, cada um à sua maneira, terem aparecido: Ke- 
vin Lynch (The Image of the City, 1960), Jane Jacobs (The Death and Life of Great American Cities, 1961), Gordon Cullen (The Concise Townscape, 1971), Philipe Panerai e Jean Castex (De lîlot à la barre, 1978), Stanford Anderson (On Streets, 1978), os ensaios precursores da Teoria da Sintaxe Espacial, de Bill Hillier e Adrian Leaman (ao longo dos anos 1970); no Brasil, tivemos a figura emblemática de Carlos Nelson Ferreira dos Santos: o trabalho profissional, os livros, e principalmente - pelo marco que foi - a histórica palestra no MAM, Rio, por ocasião da comemoração dos 50 anos do Instituto de Arquitetos do Brasil, [1971], quando ele escandalizou a corporação profissional bradando "Há cultura na favela!". O véu sobre Giovannoni começa a ser levantado, também, muito depois de Pruitt Igoe ter sido implodido (1972). Como foi forte a hegemonia do Movimento Moderno, e como durou a "profecia" de Zevi! (Mas, ao contrário do poema, sequer foi "eterna" enquanto durou...).

Um trabalho nos toca por suas qualidades intrínsecas, mas também por nossas afinidades eletivas. No caso, é-me particularmente gratificante a leitura do Cap. 2, em que Renata discorre, na obra de Giovannoni, sobre a incorporação da proteção das "belezas naturais", ou "belezas panorâmicas", objetos que "alargam a escala da conservação". Perdoem-me a gíria pessoal, mas aqui Giovannoni, embora não o diga, está tratando a paisagem natural como arquitetura, sensível às maneiras pelas quais ela -a paisagem - afeta corpos e mentes, de maneira análoga às afetações da "arquitetura artefatual" (para muitos, pleonasmo, não para mim - e, parece, também não para Giovannoni). Assim distingue-se o Cap. 1 do Cap. 2: no primeiro, o foco é, digamos, intraurbano e, apenas como artifício de ênfase, abstrai-se a paisagem; no segundo, alarga-se o foco, e o sítio natural comparece, tanto quanto o artefato urbano, na constituição do ambiente. A luta foi longa: as primeiras tentativas de normativas datam de 1922, mas o italiano teve de esperar condições políticas para materializá-las em documentos legais somente em 1939 (cuja comissão de elaboração presidiu). E, novamente, embora não exclusivamente (isso negaria a própria formação do intelectual humanista Giovannoni), a ênfase está nos aspectos expressivos dos lugares, sem que isso implique redução empobrecedora, pelo contrário.

Finalmente, destacaria a ponte entre conhecimento e uma faceta da produção concreta do espaço - o âmbito normativo, uma ponte entre teoria e prática. A ponte é o fulcro da tese. Para Renata, "o que emerge de novo é, primeiramente, a articulação direta entre o Giovan- 
noni consultor e o Giovannoni legislador". Mesmo que a historiografia tenha assinalado a importância do italiano como consultor ministerial, faltava a devida ênfase em como a essência de sua prática não se perde - pelo contrário - na passagem para o instrumento legislativo. Ótima lição de como não ficamos apenas diante do fato, de seus atributos e qualidades, e passamos ao nível do processo de sua transformação, particularmente quanto aos aspectos normativos.

A tese de Renata é um belo livro, pronto para entrar nas máquinas. 